\title{
The role of hydrogen sulfide in homocysteine-induced cardiodynamic effects and oxidative stress markers in the isolated rat heart
}

\author{
M Stojanovic ${ }^{1}$, V Zivkovic ${ }^{1}$, I Srejovic ${ }^{1}$, V Jakovljevic ${ }^{1}$, N Jeremic ${ }^{2}$, D Djuric ${ }^{3}$ \\ ${ }^{1}$ Department of Physiology, Faculty of Medical Sciences, University of Kragujevac, Kragujevac, Serbia \\ ${ }^{2}$ Department of Pharmacy, Faculty of Medical Sciences, University of Kragujevac, Kragujevac, Serbia \\ ${ }^{3}$ Institute of Medical Physiology "Richard Burian", School of Medicine, University of Belgrade, Belgrade, Serbia
}

Received: October 19, 2015

Accepted: September 19, 2016

\begin{abstract}
This study aimed to assess the role of $\mathrm{H}_{2} \mathrm{~S}$ in homocysteine-induced cardiodynamic effects in the isolated rat heart. The hearts were retrogradely perfused according to the Langendorff technique. The maximum and minimum rates of pressure in the left ventricle $(\mathrm{dp} / \mathrm{dt} \mathrm{max}, \mathrm{dp} / \mathrm{dt} \mathrm{min})$, systolic and diastolic left ventricular pressures (SLVP, DLVP), heart rate (HR), and coronary flow (CF) were measured. A spectrophotometrical method was used to measure the following oxidative stress markers: index of lipid peroxidation (thiobarbituric acid reactive substances, TBARS), nitrite level $\left(\mathrm{NO}_{2}{ }^{-}\right)$, superoxide anion radicals $\left(\mathrm{O}_{2}{ }^{--}\right)$, and hydrogen peroxide $\left(\mathrm{H}_{2} \mathrm{O}_{2}\right)$ concentrations. The administration of $10 \mu \mathrm{mol} / \mathrm{l}$ DL-homocysteine (DL-Hcy) alone decreased $\mathrm{dp} / \mathrm{dt}$ max, SLVP, and CF but did not change any oxidative stress parameters. The administration of $10 \mu \mathrm{mol} / 1$ DL-propargylglycine (DL-PAG) decreased all cardiodynamic parameters and increased the concentration of $\mathrm{O}_{2}{ }^{\bullet-}$. The co-administration of DL-Hcy and DL-PAG induced a significant decrease in all estimated cardiodynamic parameters and decreased the concentration of $\mathrm{NO}_{2}{ }^{-}$and $\mathrm{O}_{2}{ }^{-}$but increased the levels of TBARS and $\mathrm{H}_{2} \mathrm{O}_{2}$. Homocysteine shows a lower pro-oxidative effect in the presence of hydrogen sulfide $\left(\mathrm{H}_{2} \mathrm{~S}\right)$, which indicates a potential anti-oxidative capacity of $\mathrm{H}_{2} \mathrm{~S}$.
\end{abstract}

Keywords: cardiodynamics, homocysteine, $\mathrm{H}_{2} \mathrm{~S}$, Langendorff technique, oxidative stress

\section{Introduction}

Homocysteine (Hcy) is a sulfur-containing amino acid whose elevated values have a high correlation with the increased risk for cardiovascular diseases (CVDs). For this reason, hyperhomocysteinemia (HHcy) is suggested as a new and independent risk factor for developing these conditions $(38,39)$. HHcy occurs as a consequence of an impaired remethylation process or a deficiency in Hcy metabolic enzymes [cystathionine $\beta$-synthase (CBS), cystathionine $\gamma$-lyase (CSE), and 3-mercaptopyruvate sulfur transferase] (19). These three enzymes break down Hcy into hydrogen sulfide $\left(\mathrm{H}_{2} \mathrm{~S}\right)(33)$. Together with nitric oxide ( $\mathrm{NO}$ ), carbon monoxide (CO), and methane, $\mathrm{H}_{2} \mathrm{~S}$ belongs to a group of gaseous messengers whose importance in different pathophysiological processes has rapidly increased over the years $(11,23,24,30,34)$.

Corresponding author: Vladimir Zivkovic, $\mathrm{MD}, \mathrm{PhD}$

Department of Physiology, Faculty of Medical Sciences, University of Kragujevac

Svetozara Markovica 69, 34000 Kragujevac, Serbia

Phone: +38160 4227842; Fax:+38134306800 ext. 112; E-mail: vladimirziv@gmail.com 
In the cardiovascular system (CVS; the heart and aorta), $\mathrm{H}_{2} \mathrm{~S}$ is generated by CSE (45) and manifests effects opposite to those of Hcy (28). $\mathrm{H}_{2} \mathrm{~S}$ acts as a vasorelaxant (45) and an inhibitor of hypertrophy and fibrosis of vascular smooth muscle cells (17). Taking into consideration that HHcy can be caused by the inhibition of metabolic enzymes that produce $\mathrm{H}_{2} \mathrm{~S}$ from Hcy (19), the question arises whether the blockade of $\mathrm{H}_{2} \mathrm{~S}$ synthesis influence homocysteine-induced cardiac effects.

It is considered that hyperhomocysteinemia has adverse effects on the endothelium of blood vessels, mainly by increasing the production of free radicals, superoxide anion radicals $\left(\mathrm{O}_{2}{ }^{-}\right)$, and hydrogen peroxide $\left(\mathrm{H}_{2} \mathrm{O}_{2}\right)(16,22,36,39)$. The connection between the metabolism of homocysteine, free radicals, and $\mathrm{H}_{2} \mathrm{~S}$ in the CVS is still insufficiently investigated (31). However, much research has proven that $\mathrm{H}_{2} \mathrm{~S}$ is able to directly scavenge reactive oxygen species (ROS) and downregulate the ROS-producing enzymes, which indicates that $\mathrm{H}_{2} \mathrm{~S}$ is a potent vasodilator and has powerful anti-inflammatory, antioxidant, and antiapoptotic effects $(2,20,21,41-43,45)$.

To reveal the mechanisms by which homocysteine influences myocardium and coronary circulation, we aimed to investigate the role of $\mathrm{H}_{2} \mathrm{~S}$ and oxidative stress in these effects of homocysteine.

\section{Materials and Methods}

Eight-week-old male Wistar albino rats with a body mass of $250 \pm 30 \mathrm{~g}$ were kept in standard laboratory conditions (air temperature $23 \pm 10{ }^{\circ} \mathrm{C}$, relative humidity $50 \%$ ), 12:12 dark-light cycle (the beginning of the light period was at 9 a.m.) and given water and food ad libitum. All research procedures were carried out in accordance with European Directive for welfare of laboratory animals (No. 86/609/EEC) and principles of good laboratory practice, approved by ethical committee of the Faculty of Medical Sciences (Reg. No. 01-994/4), University of Kragujevac, Serbia. The rats were divided into three experimental groups (12 animals per group). The hearts of the rats were excised and perfused according to the modified Langendorff technique at constant pressure conditions (Experimetria Ltd., Budapest, Hungary) as described previously (48). The animals were premedicated with heparin as an anticoagulant, and briefly, under ether anaesthesia, were sacrificed by cervical dislocation (Schedule 1 of the Animals/Scientific Procedures, Act 1986, UK). After emergency thoracotomy and rapid cardiac arrest by superfusion with ice-cold isotonic saline, the hearts were rapidly excised; the aortas were cannulated and retrogradely perfused at the constant pressure of $70 \mathrm{~cm} \mathrm{H}_{2} \mathrm{O}$. The composition of the non-recirculating Krebs-Henseleit perfusate was as follows (in mmol/l): $\mathrm{NaCl} 118, \mathrm{KCI} 4.7, \mathrm{CaCl}_{2} \times 2 \mathrm{H}_{2} \mathrm{O} 2.5, \mathrm{MgSO}_{4} \times 7 \mathrm{H}_{2} \mathrm{O} 1.7$, $\mathrm{NaHCO}_{3} 25, \mathrm{KH}_{2} \mathrm{PO}_{4} 1.2$, glucose 11 , and pyruvate 2, equilibrated with $95 \% \mathrm{O}_{2}+5 \% \mathrm{CO}_{2}$ and warmed to $37{ }^{\circ} \mathrm{C}(\mathrm{pH} \mathrm{7.4)}$. Immediately after the normal heart rhythm returned, the sensor (transducer BS4 73-0184, Experimetria Ltd., Budapest, Hungary) was inserted through the newly damaged left atrium and mitral valve into the left ventricle for continuous monitoring of cardiac function.

To test coronary vascular reactivity, all hearts were challenged by short-term occlusions $(5-30 \mathrm{~s})$ followed by a bolus injection of $5 \mathrm{mmol} / \mathrm{l}$ adenosine $[60 \mu \mathrm{l}$ at a flow rate of $10 \mathrm{ml} / \mathrm{min}$ to elicit maximum coronary flow $(\mathrm{CF})$ ] during the stabilization period. Hearts were discarded if the flow did not increase by $100 \%$ over the control value for both tests (approximately $25 \%$ of the hearts). CF was measured using flowmetry. When the flow was 


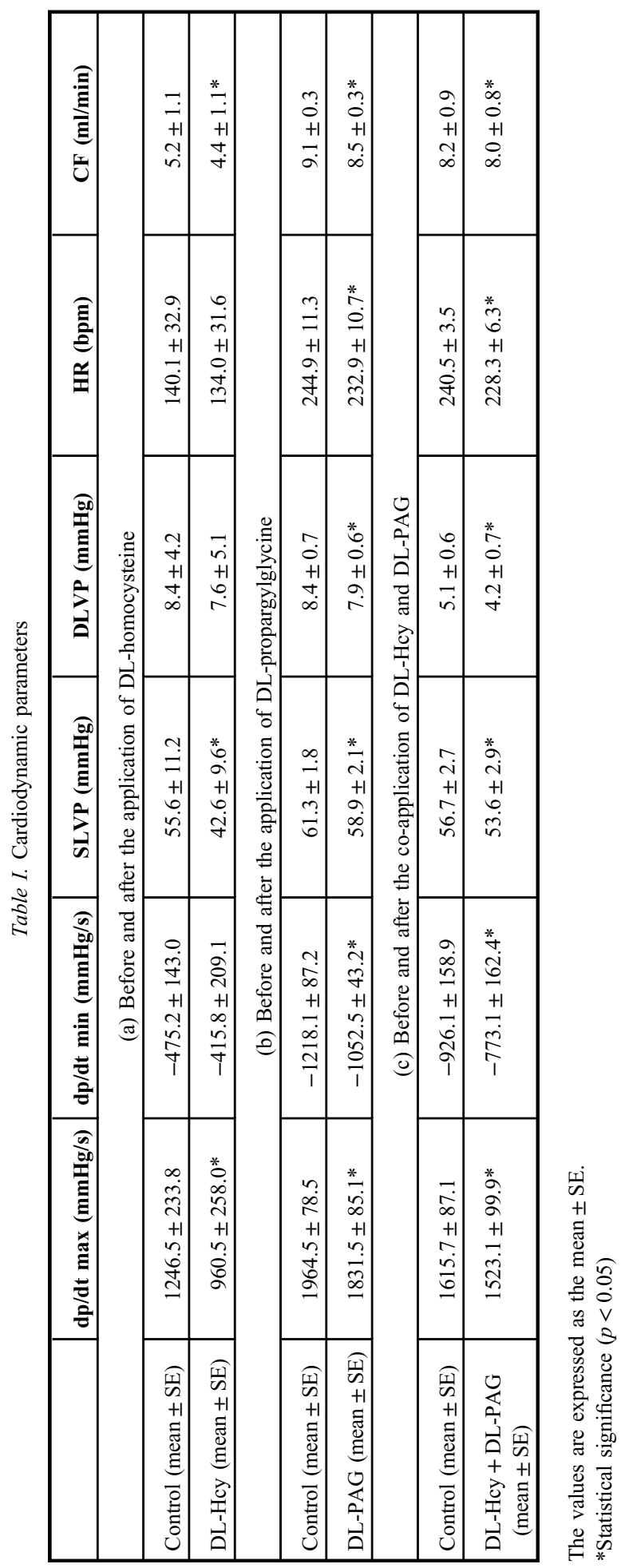


Table II. The levels of pro-oxidants in coronary venous effluent

\begin{tabular}{|c|c|c|c|c|}
\hline & $\mathrm{O}_{2}^{\bullet-}(\mathrm{nmol} / \mathrm{ml})$ & $\mathrm{H}_{2} \mathrm{O}_{2}(\mathrm{nmol} / \mathrm{ml})$ & $\mathrm{NO}_{2}^{-}(\mathrm{nmol} / \mathrm{ml})$ & TBARS $(\mu \mathrm{mol} / \mathrm{ml})$ \\
\hline \multicolumn{5}{|c|}{ (a) Before and after the application of DL-homocysteine } \\
\hline Control (mean $\pm \mathrm{SE})$ & $3.84 \pm 0.83$ & $0.48 \pm 0.05$ & $1.43 \pm 0.24$ & $0.75 \pm 0.17$ \\
\hline DL-Hcy $($ mean \pm SE) & $5.21 \pm 3.84$ & $0.45 \pm 0.02$ & $1.40 \pm 0.20$ & $0.86 \pm 0.21$ \\
\hline \multicolumn{5}{|c|}{ (b) Before and after the application of DL-propargylglycine } \\
\hline Control (mean $\pm \mathrm{SE})$ & $25.35 \pm 0.86$ & $35.76 \pm 0.52$ & $2.80 \pm 0.41$ & $23.46 \pm 1.26$ \\
\hline $\mathrm{DL}-\mathrm{PAG}($ mean $\pm \mathrm{SE})$ & $26.30 \pm 1.05^{*}$ & $34.95 \pm 1.05$ & $2.77 \pm 0.36$ & $24.82 \pm 1.00$ \\
\hline \multicolumn{5}{|c|}{ (c) Before and after the co-application of DL-Hcy and DL-PAG } \\
\hline Control $($ mean $\pm \mathrm{SE})$ & $81.46 \pm 1.85$ & $6.47 \pm 0.45$ & $18.11 \pm 0.85$ & $6.25 \pm 0.83$ \\
\hline $\begin{array}{l}\text { DL-Hcy + DL-PAG } \\
(\text { mean } \pm \text { SE })\end{array}$ & $63.36 \pm 1.89^{*}$ & $8.02 \pm 0.49^{*}$ & $15.43 \pm 0.74^{*}$ & $12.01 \pm 0.96^{*}$ \\
\hline
\end{tabular}

The values are expressed as the mean $\pm \mathrm{SE}$.

* Statistical significance $(p<0.05)$

considered stable (three measurements with the same value), coronary effluent samples were collected.

After perfusion in the absence of any substance (control conditions), the hearts were perfused as follows:

Group 1: $10 \mu \mathrm{mol} / 1$ DL-homocysteine (DL-Hcy)

Group 2: $10 \mu \mathrm{mol} / 1$ DL-propargylglycine (DL-PAG) - irreversible CSE inhibitor

Group 3: $10 \mu \mathrm{mol} / 1 \mathrm{DL}-\mathrm{Hcy}+10 \mu \mathrm{mol} / \mathrm{l} \mathrm{DL}-\mathrm{PAG}$

Groups were chosen to separate the independent influence of homocysteine (Group 1) or the endogenous CSE/ $\mathrm{H}_{2} \mathrm{~S}$ pathway (Group 2) and to estimate the role of $\mathrm{H}_{2} \mathrm{~S}$ in the cardiac effects of homocysteine (Group 3). Each of the applied substances was perfused for a duration of $5 \mathrm{~min}$. The substances were first dissolved in Krebs-Henseleit solution and, after control conditions, applied directly to the heart by perfusion pump.

By placing the sensor in the left ventricle, the following parameters of myocardial function were continuously registered:

(1) Maximum rate of pressure development in the left ventricle ( $\mathrm{dp} / \mathrm{dt} \max )$;

(2) Minimum rate of pressure development in the left ventricle (dp/dt $\mathrm{min}$ );

(3) Systolic left ventricular pressure (SLVP);

(4) Diastolic left ventricular pressure (DLVP);

(5) Heart rate (HR).

$\mathrm{CF}$ was measured using the flowmetric method and expressed in $\mathrm{ml} / \mathrm{min}$.

Coronary venous effluent $(5 \mathrm{ml})$ was collected at the same time, at the end of control conditions and during the last minute of perfusion with any of the test compounds. Oxidative stress parameters [the index of lipid peroxidation (thiobarbituric acid reactive substances, TBARS), the superoxide anion radical $\left(\mathrm{O}_{2}{ }^{-}\right), \mathrm{H}_{2} \mathrm{O}_{2}$, and nitrite $\left(\mathrm{NO}_{2}{ }^{-}\right)$] were determined in coronary venous effluent samples using the spectrophotometric method (Specord S-600 Analytik Jena). 
Determination of the index of lipid peroxidation (TBARS)

The degree of lipid peroxidation in the coronary venous effluent was estimated by measuring TBARS using $1 \%$ thiobarbituric acid in $0.05 \mathrm{NaOH}$ incubated with the coronary effluent at $100^{\circ} \mathrm{C}$ for $15 \mathrm{~min}$ and read at $530 \mathrm{~nm}$. Krebs-Henseleit solution was used as a blank probe (27).

\section{Determination of superoxide anion radical $\left(\mathrm{O}_{2}{ }^{--}\right)$}

The level of the superoxide anion radical $\left(\mathrm{O}_{2}{ }^{-}\right)$was measured by nitro blue tetrazolium reaction in Tris-buffer with coronary venous effluent and read at $530 \mathrm{~nm}$. Krebs-Henseleit solution was used as a blank probe (4).

\section{Determination of hydrogen peroxide $\left(\mathrm{H}_{2} \mathrm{O}_{2}\right)$}

The measurement of $\mathrm{H}_{2} \mathrm{O}_{2}$ was based on the oxidation of phenol red by $\mathrm{H}_{2} \mathrm{O}_{2}$ in a reaction catalyzed by horseradish peroxidase (HRPO) (29). The volume of $200 \mu \mathrm{l}$ of perfusate was precipitated with $800 \mu \mathrm{l}$ of fresh phenol red solution along with $10 \mu \mathrm{l}$ 1:20 HRPO (made ex tempore). An adequate volume of Krebs-Henseleit solution was used for a blank probe (instead of coronary venous effluent). The level of $\mathrm{H}_{2} \mathrm{O}_{2}$ was measured at $610 \mathrm{~nm}$.

\section{Determination of the nitrite level $\left(\mathrm{NO}_{2}^{-}\right)$}

The nitrite level $\left(\mathrm{NO}_{2}{ }^{-}\right)$was measured as an index of ${ }^{\circ} \mathrm{NO}$ production using the Griess reagent. A total of $0.5 \mathrm{ml}$ of perfusate was precipitated with $200 \mu \mathrm{l}$ of $30 \%$ sulfosalicylic acid, vortexed for $30 \mathrm{~min}$, and centrifuged at 3,000 $\times \mathrm{g}$. Equal volumes of the supernatant and Griess reagent, containing $1 \%$ sulfanilamide in $5 \%$ phosphoric acid, $0.1 \%$ naphthalene ethylenediamine dihydrochloride were added, incubated for $10 \mathrm{~min}$ in the dark, and read at $543 \mathrm{~nm}$. The nitrite levels were calculated using sodium nitrite as the standard (15).

All drugs were purchased from Sigma-Aldrich Chemie GmbH, Germany.

\section{Statistical data processing}

Statistical processes have been performed using the SPSS Statistics 19 program (IBM Corp., Armonk, USA). Variables are presented as mean values \pm standard deviation. We used nonparametric methods (Wilcoxon test) to calculate the significance of the differences between the data. A value of $p<0.05$ is considered statistically significant. After statistical processing of the data, the results were shown in tables.

\section{Results}

The effects of DL-Hcy, DL-PAG, and DL-Hcy + DL-PAG on myocardial function parameters in the isolated rat heart

The administration of DL-Hcy on an isolated rat heart induced a significant decrease of the $\mathrm{dp} / \mathrm{dt}$ max, SLVP and CF, compared to control conditions (Table Ia).

The administration of DL-PAG induced a significant decrease of all the estimated cardiodynamic parameters (Table Ib).

The effects of DL-Hcy and DL-PAG co-administration also induced a significant decrease of all the estimated cardiodynamic parameters (Table Ic).

The effects of DL-Hcy, DL-PAG, DL-Hcy $+D L-P A G$ on oxidative stress markers in the isolated rat heart

Perfusion with DL-Hcy showed that there were no significant changes in the levels of all the estimated oxidative stress parameters in the coronary venous effluent (Table IIa). 
The administration of DL-PAG induced a significant increase in the levels of $\mathrm{O}_{2}{ }^{-{ }^{-}}$in the coronary venous effluent, whereas other parameters of oxidative stress showed no statistically significant differences (Table IIb).

The effects of DL-Hcy and DL-PAG co-administration on oxidative stress parameters induced a significant decrease in the levels of $\mathrm{NO}_{2}$ and $\mathrm{O}_{2}{ }^{-}$, and a significant increase in TBARS and $\mathrm{H}_{2} \mathrm{O}_{2}$ (Table IIc).

\section{Discussion}

One of the objectives of this study was to examine the direct effects of the basic form of homocysteine on the myocardium and the coronary circulation in the isolated rat heart. Although it has been well known that homocysteine has an increasingly significant role in the pathophysiology of CVDs $(1,12)$, the majority of investigations examined the influence of homocysteine on the vascular system $(3,25)$, while the effects on the myocardium and the coronary circulation are little known.

The results obtained show that homocysteine leads to a significant reduction of the following major cardiodynamic parameters: dp/dt max and SLVP, and also CF (Table Ia).

Related to our research, and with respect to the similarity with our experimental model, Kennedy et al. (18) studied the acute effects of homocysteine (30-100 $\mu \mathrm{mol})$ on systolic function and contractibility of myocardium; they found similar results in that there was a significant reduction of systolic function and contractive abilities ( $\mathrm{dp} / \mathrm{dt}$ max) in the isolated rat heart, but no changes in diastolic function were recorded, regardless of the applied dose.

Wan et al. (40) examined the effects of homocysteine in a cardiac ischemia model. The study showed that homocysteine reduced the contractible ability ( $\mathrm{dp} / \mathrm{dt}$ max), but without the effect on SLVP, DLVP and HR, which was very similar to our findings. Although our research was performed on healthy hearts, it is obvious that homocysteine in both normoxic and hypoxic conditions, either acutely or chronically administered, has a direct negative effect on cardiac function. One of the potential explanations for such results may be the fact that DL-Hcy, via still unknown mechanisms, showed cardiotoxic effects on cultured isolated cardiomyocytes (35).

On the other hand, it has been documented that gasotransmitters ( $\mathrm{NO}, \mathrm{CO}$, and $\mathrm{H}_{2} \mathrm{~S}$ ) are increasingly important in various pathophysiological states in the heart. Using the same Langendorff apparatus, Bak et al. (5-7) have shown that $\mathrm{CO}$ could be a powerful tool for functional recovery of post-ischemic rat or mouse heart. $\mathrm{H}_{2} \mathrm{~S}$ is a biologically active gas whose role in the effects of homocysteine on the heart was investigated. In the conditions when there is enough methionine and homocysteine, homocysteine is subject to the process of transsulfuration when it converts into cystathionine with the help of the enzyme CBS in the presence of serine. Then, under the influence of the other enzyme CSE, cystathionine metabolizes to L-cysteine to finally generate $\mathrm{H}_{2} \mathrm{~S}, \alpha$-keto barbiturates and ammonium (32). It implies that this signal molecule may have an influence on the effects of homocysteine on the CVS.

The effects of endogenous and exogenous $\mathrm{H}_{2} \mathrm{~S}$ on the CVS have been intensively investigated, but the data obtained are still incoherent and without precise conclusions (32, 46). Much less is known about the effects of $\mathrm{H}_{2} \mathrm{~S}$ on the myocardium and the coronary circulation. We decided to inhibit the enzyme CSE, which is supposed to be an endogenous source of $\mathrm{H}_{2} \mathrm{~S}$ in the heart (13), by the administration of DL-PAG. The administration of 
DL-PAG leads to a considerable reduction of all the examined cardiodynamic parameters, although the function and perfusion of the myocardium were weakened (Table $\mathrm{Ib}$ ).

In comparison to our study, Carson et al. (9) studied the effects of $\mathrm{H}_{2} \mathrm{~S}$ on the myocardium and coronary perfusion in the same experimental model (Langendorff retrograde perfusion). This group showed that exogenously administered $\mathrm{H}_{2} \mathrm{~S}$ induced a dosedependent reduction of $\mathrm{dp} / \mathrm{dt} \max$ and min like in the HR of the isolated rat heart, while paradoxically increasing the CF. In comparison to our study, these results could be due to different experimental approaches (exogenous uptake).

Although they are still unclear, the mechanisms by which $\mathrm{H}_{2} \mathrm{~S}$ influences the heart and coronary circulation probably include activation of $\mathrm{K}_{\mathrm{ATP}}$ channels in both cardiomyocytes (47) and coronary smooth muscles (37). Despite the insufficient knowledge of the role of $\mathrm{H}_{2} \mathrm{~S}$ in the heart functioning, the coronary circulation and the discrepancy between the existing data, this gasotransmitter can obviously be synthesized in the heart, and together with ${ }^{\circ} \mathrm{NO}$ and $\mathrm{CO}$ may be significant in the pathophysiology of the heart.

In our study, the potential role of $\mathrm{H}_{2} \mathrm{~S}$ in the effects of homocysteine on the myocardium and coronary vascular tonus was examined by the combined administration of homocysteine with a CSE inhibitor (DL-PAG). The administration of DL-PAG with DL-Hcy statistically significantly reduced the values of all cardiodynamic parameters (Table Ic).

In a study that used an experimental model similar to ours, the influence of $\mathrm{H}_{2} \mathrm{~S}$ on the infarction of myocardium in rats with hyperhomocysteinemia was examined (10). This research showed that in the case of development of hyperhomocysteinemia, myocardium expression and activity of CSE, and hence $\mathrm{H}_{2} \mathrm{~S}$, were significantly reduced. On the other hand, the administration of $\mathrm{H}_{2} \mathrm{~S}$ during the period prior to ischemia improved functional recovery of the heart and reduced the bulk of infarction, which showed that $\mathrm{H}_{2} \mathrm{~S}$ could be significant in the ischemic preconditioning and reperfusion period.

The connection between homocysteine and oxidative stress has long been known. Like all thiols, homocysteine easily enters the processes of oxidation such as self-oxidation in plasma. During the oxidation of the sulfhydryl group, homocysteine generation of various ROS occurs, above all $\mathrm{O}_{2}{ }^{--}, \mathrm{H}_{2} \mathrm{O}_{2}$, and $\mathrm{OH}^{--}$. These ROS then initiate lipid peroxidation of vascular endothelial cells and their morphofunctional disorder. The $\mathrm{O}_{2}{ }^{-}$interacts with $\mathrm{NO}$ produced by the same cells, thereby generating even more toxic reactive nitrogen species $\mathrm{ONOO}^{\circ}$. Thus, the damage to endothelial cells impairs the control of vascular tonus and leads to the endothelial dysfunction $(16,22,36,39)$.

One of the studies showed that homocysteine increased the production of pro-oxidation markers (TBARS) and reduced the activity of anti-oxidation enzymes of protection in the rat heart (26). The results of our study indicate that after the application of the basic homocysteine form (Table IIa), there were no significant changes in the values of all examined oxidative stress markers. In our case, the effects of acutely administered homocysteine were examined, whereas the previous research treated chronic effects. In addition, the dose of homocysteine in the present study was incomparably smaller to lead to possible damage. Additionally, it should be noted that our model was based on physiological conditions of cardiac function.

We wanted to examine a potential role of $\mathrm{H}_{2} \mathrm{~S}$ in the stimulation of oxidative stress. The majority of available data show that $\mathrm{H}_{2} \mathrm{~S}$ often reduces the production of ROS, i.e., it has an anti-oxidative character in the CVS (2, 20, 21, 41-43, 45). In our study, the administration of the inhibitor $\mathrm{CSE} / \mathrm{H}_{2} \mathrm{~S}$ system (DL-PAG) induced the increased release of superoxide anion radicals in coronary venous effluent, while the levels of other parameters in the oxidative 
stress did not show statistically significant change in comparison to the control conditions (Table IIb).

Our results are in accordance with those of Gao et al. (14), who examined the influence of exogenous (NaHS) and endogenous $\mathrm{H}_{2} \mathrm{~S}$ (DL-PAG) on the development of oxidative stress during ischemia and reperfusion of myocardium. They showed that the $\mathrm{H}_{2} \mathrm{~S}$ donor, $\mathrm{NaSH}$, was related to the reduced lipid peroxidation, ROS production, and consequent decrease of the size of infarction. On the other hand, the blockage of synthesis of endogenous $\mathrm{H}_{2} \mathrm{~S}$ induced opposite effects. These findings show that $\mathrm{H}_{2} \mathrm{~S}$ could have a cardioprotective effect.

Based on these results, we can assume that $\mathrm{H}_{2} \mathrm{~S}$, either exogenous or endogenous, seems to possess a certain anti-oxidative capacity that should be confirmed in further studies. Additionally, future research should be extended to use a wider range of administered doses to determine possible dose-dependence of the obtained effects.

It remains little known how significant $\mathrm{H}_{2} \mathrm{~S}$ is in the oxidative effects in the presence of homocysteine. According to the latest data, $\mathrm{H}_{2} \mathrm{~S}$ can reduce the endothelial stress induced by homocysteine $(8,10)$. Namely, endothelial cells are capable of secreting CBS and CSE enzymes, which then, while circulating, actively generate $\mathrm{H}_{2} \mathrm{~S}$ from homocysteine (8). In the presence of homocysteine, the $\mathrm{H}_{2} \mathrm{~S}$ synthesized in this way prevents oxidative damage and consequent dysfunction of endothelial cells $(8,10,44)$.

Yan et al. (44) examined whether $\mathrm{H}_{2} \mathrm{~S}$ could influence the cytotoxicity and oxidative stress induced by homocysteine. Cultures of smooth aortic muscles were exposed to homocysteine in the presence or absence of an $\mathrm{H}_{2} \mathrm{~S}$ donor (NaHS) in increasing doses. The study showed that homocysteine in combination with small concentrations of $\mathrm{H}_{2} \mathrm{~S}$ reduced the production of $\mathrm{H}_{2} \mathrm{O}_{2}, \mathrm{ONOO}^{--}$and $\mathrm{O}_{2}{ }^{--}$, and cell damage. The results of our study show that after the co-administration of DL-Hcy and DL-PAG, the levels of $\mathrm{NO}_{2}{ }^{-}$and $\mathrm{O}_{2}{ }^{--}$statistically significantly decreased, while TBARS and $\mathrm{H}_{2} \mathrm{O}_{2}$ increased (Table IIc), so we cannot find a dominant trend in the dynamics of these parameters. In the case of the basic forms of homocysteine, $\mathrm{H}_{2} \mathrm{~S}$ does not yet have a precise pro- or anti-oxidative potential. However, in contrast to other studies (44), we examined the effects of endogenous $\mathrm{H}_{2} \mathrm{~S}$.

\section{Conclusion}

The acute and direct effects of homocysteine on the isolated rat heart imply negative inotropic and lusitropic effects and a vasoconstrictor influence on the coronary endothelium. The inhibition of $\mathrm{H}_{2} \mathrm{~S}$ synthesis led to complete depression of cardiodynamics, which showed that these gasotransmitters can play a role in the contraction of cardiomyocytes and the control of coronary vascular tonus. Homocysteine and $\mathrm{H}_{2} \mathrm{~S}$ did not contribute to the development of oxidative stress in this study, which means that acute cardiodynamic effects are possibly not mediated by oxidative damage. It also seems that $\mathrm{H}_{2} \mathrm{~S}$ has certain anti-oxidative capacities, which should be definitely confirmed in further studies. It seems that homocysteine shows a lower pro-oxidative effect in the presence of $\mathrm{H}_{2} \mathrm{~S}$ in comparison to the absence of production of this signal molecule, which indicates a potential anti-oxidative capacity of the mentioned gasotransmitter.

\section{Acknowledgement}

This project was supported by a grant (No. 175043) from the Ministry of Science and Technical Development of the Republic of Serbia, and the Junior Project 04/2011, Faculty of Medical Sciences, University of Kragujevac, Serbia. 


\section{REFERENCES}

1. Ahluwalia N, Blacher J, Szabo de Edelenyi F, Faure P, Julia C, Hercberg S, Galan P: Prognostic value of multiple emerging biomarkers in cardiovascular risk prediction in patients with stable cardiovascular disease. Atherosclerosis 228, 478-484 (2013)

2. Ali MY, Ping CY, Mok YY, Ling L, Whiteman M, Bhatia M, Moore PK: Regulation of vascular nitric oxide in vitro and in vivo; a new role for endogenous hydrogen sulphide? Br. J. Pharmacol. 149, 625-634 (2006)

3. Alsulaimani S, Gardener H, Elkind MS, Cheung K, Sacco RL, Rundek T: Elevated homocysteine and carotid plaque area and densitometry in the Northern Manhattan Study. Stroke 44, 457-461 (2013)

4. Auclair C, Voisin E (1985): Nitroblue tetrazolium reduction. In: Handbook of Methods for Oxygen Radical Research, ed Greenwald RA, CRC Press, Boca Raton, FL, USA, pp. 123-132

5. Bak I, Czompa A, Juhasz B, Lekli I, Tosaki A: Reduction of reperfusion-induced ventricular fibrillation and infarct size via heme oxygenase-1 overexpression in isolated mouse hearts. J. Cell. Mol. Med. 14, 2268-2272 (2010)

6. Bak I, Papp G, Turoczi T, Varga E, Szendrei L, Vecsernyes M, Joo F, Tosaki A: The role of heme oxygenaserelated carbon monoxide and ventricular fibrillation in ischemic/reperfused hearts. Free Radic. Biol. Med. 33, 639-648 (2002)

7. Bak I, Varadi J, Nagy N, Vecsernyes M, Tosaki A: The role of exogenous carbon monoxide in the recovery of post-ischemic cardiac function in buffer perfused isolated rat hearts. Cell. Mol. Biol. (Noisy-le-grand) 51, 453-459 (2005)

8. Bearden SE, Beard RS Jr, Pfau JC: Extracellular transsulfuration generates hydrogen sulfide from homocysteine and protects endothelium from redox stress. Am. J. Physiol. Heart Circ. Physiol. 299, H1568-H1576 (2010)

9. Carson RJ, Seyffarth G, Mian R, Maddock H (2004): Interactions between gasotransmitters. In: Signal Transduction and the Gasotransmitters: $\mathrm{NO}, \mathrm{CO}$ and $\mathrm{H}_{2} \mathrm{~S}$ in Biology and Medicine, ed Wang R, Humana Press, NJ, USA, pp. 33-55

10. Chang L, Geng B, Yu F, Zhao J, Jiang H, Du J, Tang C: Hydrogen sulfide inhibits myocardial injury induced by homocysteine in rats. Amino Acids 34, 573-585 (2008)

11. Chen O, Ye Z, Cao Z, Manaenko A, Ning K, Zhai X, Zhang R, Zhang T, Chen X, Liu W, Sun X: Methane attenuates myocardial ischemia injury in rats through anti-oxidative, anti-apoptotic and anti-inflammatory actions. Free Radic. Biol. Med. 90, 1-11 (2016)

12. Delles C: Homocysteine and the very elderly: is there a message for cardiovascular risk? J. Hypertens. 31 , 874-876 (2013)

13. Fu M, Zhang W, Yang G, Wang R: Is cystathionine gamma-lyase protein expressed in the heart? Biochem. Biophys. Res. Commun. 428, 469-474 (2012)

14. Gao Y, Yao X, Zhang Y, Li W, Kang K, Sun L, Sun X: The protective role of hydrogen sulfide in myocardial ischemia-reperfusion-induced injury in diabetic rats. Int. J. Cardiol. 152, 177-183 (2011)

15. Green LC, Wagner DA, Glogowski J, Skipper PL, Wishnok JS, Tannenbaum SR: Analysis of nitrate, nitrite, and [15N] nitrate in biological fluids. Anal. Biochem. 126, 131-138 (1982)

16. Harker LA, Ross R, Slichter SJ, Scott CR: Homocystine-induced arteriosclerosis. The role of endothelial cell injury and platelet response in its genesis. J. Clin. Invest. 58, 731-741 (1976)

17. Huang J, Wang D, Zheng J, Huang X, Jin H: Hydrogen sulfide attenuates cardiac hypertrophy and fibrosis induced by abdominal aortic coarctation in rats. Mol. Med. Rep. 5, 923-928 (2012)

18. Kennedy RH, Owings R, Shekhawat N, Joseph J: Acute negative inotropic effects of homocysteine are mediated via the endothelium. Am. J. Physiol. Heart Circ. Physiol. 287, H812-H817 (2004)

19. Kesherwani V, Nandi SS, Sharawat SK, Shahshahan HR, Mishra PK: Hydrogen sulfide mitigates homocysteinemediated pathological remodeling by inducing miR-133a in cardiomyocytes. Mol. Cell. Biochem. 404, 241-250 (2015)

20. Kimura Y, Kimura H: Hydrogen sulfide protects neurons from oxidative stress. FASEB J. 18, 1165-1167 (2004)

21. Laggner H, Muellner MK, Schreier S, Sturm B, Hermann M, Exner M, Gmeiner BM, Kapiotis S: Hydrogen sulphide: a novel physiological inhibitor of LDL atherogenic modification by HOCl. Free Radic. Res. 41, 741-747 (2007)

22. Lang D, Kredan MB, Moat SJ, Hussain SA, Powell CA, Bellamy MF, Powers HJ, Lewis MJ: Homocysteineinduced inhibition of endothelium-dependent relaxation in rabbit aorta: role for superoxide anions. Arterioscler. Thromb. Vasc. Biol. 20, 422-427 (2000) 
23. Li L, Hsu A, Moore PK: Actions and interactions of nitric oxide, carbon monoxide and hydrogen sulphide in the cardiovascular system and in inflammation - a tale of three gases! Pharmacol. Ther. 123, 386-400 (2009)

24. Meyer G, André L, Kleindienst A, Singh F, Tanguy S, Richard S, Obert P, Boucher F, Jover B, Cazorla O, Reboul C: Carbon monoxide increases inducible NOS expression that mediates CO-induced myocardial damage during ischemia-reperfusion. Am. J. Physiol. Heart Circ. Physiol. 308, H759-H767 (2015)

25. Nilsson K, Gustafson L, Hultberg B: Elevated plasma homocysteine level in vascular dementia reflects the vascular disease process. Dement. Geriatr. Cogn. Dis. Extra. 3, 16-24 (2013)

26. Norsidah KZ, Asmadi AY, Azizi A, Faizah O, Kamisah Y: Palm tocotrienol-rich fraction reduced plasma homocysteine and heart oxidative stress in rats fed with a high-methionine diet. J. Physiol. Biochem. 69, 441-449 (2013)

27. Ohkawa H, Ohishi N, Yagi K: Assay for lipid peroxides in animal tissues by thiobarbituric acid reaction. Anal. Biochem. 95, 351-358 (1979)

28. Patel VB, McLean BA, Chen X, Oudit GY: Hydrogen sulfide: an old gas with new cardioprotective effects. Clin. Sci. (Lond.) 128, 321-323 (2015)

29. Pick E, Keisari Y: A simple colorimetric method for the measurement of hydrogen peroxide produced by cells in culture. J. Immunol. Methods 38, 161-170 (1980)

30. Polhemus DJ, Lefer DJ: Emergence of hydrogen sulfide as an endogenous gaseous signaling molecule in cardiovascular disease. Circ. Res. 114, 730-737 (2014)

31. Pushpakumar S, Kundu S, Sen U: Endothelial dysfunction: the link between homocysteine and hydrogen sulfide. Curr. Med. Chem. 21, 3662-3672 (2014)

32. Reiffenstein RJ, Hulbert WC, Roth SH: Toxicology of hydrogen sulfide. Annu. Rev. Pharmacol. Toxicol. 32, 109-134 (1992)

33. Sen U, Mishra PK, Tyagi N, Tyagi SC: Homocysteine to hydrogen sulfide or hypertension. Cell Biochem. Biophys. 57, 49-58 (2010)

34. Shen Y, Shen Z, Luo S, Guo W, Zhu YZ: The cardioprotective effects of hydrogen sulfide in heart diseases: from molecular mechanisms to therapeutic potential. Oxid. Med. Cell. Longev. 2015, 925167 (2015)

35. Sipkens JA, Krijnen PA, Meischl C, Cillessen SA, Smulders YM, Smith DE, Giroth CP, Spreeuwenberg MD, Musters RJ, Muller A, Jakobs C, Roos D, Stehouwer CD, Rauwerda JA, van Hinsbergh VW, Niessen HW: Homocysteine affects cardiomyocyte viability: concentration-dependent effects on reversible flip-flop, apoptosis and necrosis. Apoptosis 12, 1407-1418 (2007)

36. Starkebaum G, Harlan JM: Endothelial cell injury due to copper-catalyzed hydrogen peroxide generation from homocysteine. J. Clin. Invest. 77, 1370-1376 (1986)

37. Sun Y, Tang CS, Jin HF, Du JB: The vasorelaxing effect of hydrogen sulfide on isolated rat aortic rings versus pulmonary artery rings. Acta Pharmacol. Sin. 32, 456-464 (2011)

38. The Homocysteine Studies Collaboration: Homocysteine and risk of ischemic heart disease and stroke: a metaanalysis. JAMA 288, 2015-2022 (2002)

39. Wall RT, Harlan JM, Harker LA, Striker GE: Homocysteine-induced endothelial cell injury in vitro: a model for the study of vascular injury. Thromb. Res. 18, 113-121 (1980)

40. Wan J, Deng Y, Guo J, Xiao G, Kuang D, Zhu Y, Duan Y, Wang G: Hyperhomocysteinemia inhibited cardiac stem cell homing into the peri-infarcted area post myocardial infarction in rats. Exp. Mol. Pathol. 91, 411-418 (2011)

41. Wang R: Two's company, three's a crowd: can $\mathrm{H}_{2} \mathrm{~S}$ be the third endogenous gaseous transmitter? FASEB J. 16, 1792-1798 (2002)

42. Whiteman M, Armstrong JS, Chu SH, Jia-Ling S, Wong BS, Cheung NS, Halliwell B, Moore PK: The novel neuromodulator hydrogen sulfide: an endogenous peroxynitrite 'scavenger'? J. Neurochem. 90, 765-768 (2004)

43. Whiteman M, Cheung NS, Zhu YZ, Chu SH, Siau JL, Wong BS, Armstrong JS, Moore PK: Hydrogen sulphide: a novel inhibitor of hypochlorous acid-mediated oxidative damage in the brain? Biochem. Biophys. Res. Commun. 326, 794-978 (2005)

44. Yan SK, Chang T, Wang H, Wu L, Wang R, Meng QH: Effects of hydrogen sulfide on homocysteine-induced oxidative stress in vascular smooth muscle cells. Biochem. Biophys. Res. Commun. 351, 485-491 (2006)

45. Yang G, Wu L, Jiang B, Yang W, Qi J, Cao K, Meng Q, Mustafa AK, Mu W, Zhang S, Snyder SH, Wang R: $\mathrm{H}_{2} \mathrm{~S}$ as a physiologic vasorelaxant: hypertension in mice with deletion of cystathionine gamma-lyase. Science 322 , 587-590 (2008) 
46. Zhao W, Zhang J, Lu Y, Wang R: The vasorelaxant effect of $\mathrm{H}_{2} \mathrm{~S}$ as a novel endogenous gaseous $\mathrm{K}_{\mathrm{ATP}}$ channel opener. EMBO J. 20, 6008-6016 (2001)

47. Zhong GZ, Li YB, Liu XL, Guo LS, Chen ML, Yang XC: Hydrogen sulfide opens the $\mathrm{K}_{\text {ATP }}$ channel on rat atrial and ventricular myocytes. Cardiology 115, 120-126 (2010)

48. Zivkovic V, Jakovljevic V, Djordjevic D, Vuletic M, Barudzic N, Djuric D: The effects of homocysteine-related compounds on cardiac contractility, coronary flow, and oxidative stress markers in isolated rat heart. Mol. Cell. Biochem. 370, 59-67 (2012) 